UDC 316.346 .32

LBC 60.561

\title{
THE PUBLIC OPINION STUDY AS A WAY TO OPTIMIZE THE POLICE ACTIVITY ${ }^{1}$
}

\author{
Olga V. Zueva \\ Volgograd Academy of the Russian Internal Affairs Ministry, Volgograd, Russian Federation
}

\begin{abstract}
The article deals with the problem of public opinion study as the principal method of optimizing the police activity. The author considers that public opinion as a form of social consciousness determines communicative processes and influences on the government activity, including internal affairs bodies' activity. The qualitative assessment of the police activity that is expressed in the analysis of the public opinion of the citizens concerning the internal affairs bodies'activity allows making the most objective conclusions on their activity effectiveness.

The author noted the criteria for the evaluation of the internal affairs bodies'activity which include: citizens' confidence in protection of their personal and property interests; the public confidence in the police, the sense of personal security, citizens' willingness to support the police. The measurement of the given criteria is carried out by means of the empirical studies involving the direct participation of the author of the article. The analysis of the empirical data showed an increased percentage of the positive assessments of the citizens who express their confidence in the protection of their personal and property interests, as well as, some growth of the level of trust in the police. The author pays attention to the fact that, in spite of the positive trends in the citizens evaluation of the police activity after internal affairs bodies reforming, there is still a large reserve for constructive cooperation of the population with the police.

In conclusion the author points out that the police activity optimization is possible with continuous monitoring of the public opinion in the form of the open dialogue with the population will lead to the police ability to respond to the constructive proposals of the population in order to optimize their activity.
\end{abstract}

Key words: public opinion on internal affairs bodies' activity, monitoring the police activity, criteria for evaluation of the police activity, personal and property protection, the police's credibility.

удК 316.346 .32

ББК 60.561

\section{ИЗУЧЕНИЕ ОБЩЕСТВЕННОГО МНЕНИЯ КАК СПОСОБ ОПТИМИЗАЦИИ ДЕЯТЕЛЬНОСТИ ПОЛИЦИИ ${ }^{1}$}

\author{
Ольга Владимировна Зуева \\ Волгоградская академия МВД России, г. Волгоград, Российская Федерация
}

\begin{abstract}
Аннотация. В работе рассмотрена проблема изучения общественного мнения как основного способа оптимизации деятельности полиции. Автор полагает, что общественное мнение, являясь формой общественного сознания, определяет коммуникативные процессы и влияет на государственную деятельность, в том числе на деятельность органов внутренних дел. Качественная оценка деятельности полиции, выражающаяся в анализе общественного мнения о деятельности органов внутренних дел, позволяет делать наиболее объективные выводы, касающиеся эффективности их работы.

Отмечены основные критерии оценки деятельности полиции, такие как уверенность граждан в защищенности своих интересов; уровень доверия к полиции, ощущение личной безопасности, готовность граждан оказать поддержку полиции. Измерение выделенных критериев осуществляется при помощи эмпирических исследований, проведенных при непосредственном участии автора статьи. В ходе анализа эмпирических данных обнаружено увеличение доли положительных оценок граждан, выражающих уверенность последних в защищенности как личных, так и имущественных интересов, а также рост уровня доверия к () полиции. Автор обращает внимание на то, что, несмотря на наметившуюся позитивную тенденцию в оценке
\end{abstract}


гражданами деятельности полиции после начала реформирования органов внутренних дел, еще имеется достаточно большой резерв для конструктивного сотрудничества населения с полицией.

В заключении подчеркивается, что оптимизация деятельности полиции возможна при постоянном мониторинге общественного мнения. Только открытый диалог с населением приведет к тому, что полиция будет способна реагировать на конструктивные предложения граждан по оптимизации своей деятельности.

Ключевые слова: общественное мнение о деятельности ОВД, критерии оценки деятельности полиции, контроль за деятельностью полиции, личная и имущественная безопасность, доверие к полиции.

Процесс институционализации гражданского общества в России тесно связан с формированием общественного мнения. Являясь социально-психологическим феноменом, общественное мнение заключает в себе явное или скрытое отношение всего общества или его отдельной части к событиям, явлениям и проблемам социальной действительности. Выражая нравственность общества, общественную мораль, оно способно влиять на государственную деятельность через формы представительной демократии. Изучение общественного мнения в современной России дает репрезентативные результаты, поскольку оно не зависимо от силовых структур и политических институтов. Граждане свободно могут высказываться по злободневным проблемам и острым вопросам.

Каждое дело, тем более такое важное государственное направление, как правоохранительная деятельность, нуждается в оценке. Органы правопорядка, принадлежащие системе исполнительной власти, подлежат объективной оценке и контролю со стороны общества и государства. В соответствии с п. 1 ст. 49 Федерального закона «О полиции» от 7 февраля 2011 г. № 3-Ф3 государственный контроль за деятельностью полиции в пределах своих полномочий осуществляют президент, верхняя и нижняя палаты Федерального собрания, Правительство Российской Федерации [6]. Однако у перечисленных органов имеется множество прямых обязанностей, а контроль за деятельностью полиции для них вторичен и поэтому слабо выполним. В настоящее время дают оценку и осуществляют контроль за деятельностью полиции главным образом ведомственные структуры.

Однако такие понятия, как контроль за деятельностью полиции и оценка деятельности полиции, необходимо различать. Контроль за деятельностью полиции, механизм которого в МВД достаточно отработан, - это общее поня- тие, которое включает в себя и оценку деятельности полиции. А вот вопрос относительно оценки деятельности полиции остается открытым, и с ним необходимо разобраться.

Существующая в дореформенный период система оценки деятельности на тот момент еще милиции, основанная на данных статистики, показала свою несостоятельность, так как не отражает в полной мере реальное положение дел в правоохранительной системе и не учитывает общественное мнение.

На сегодняшний момент согласно ст. 9 Федерального закона «О полиции» основным критерием для оценки деятельности полиции можно назвать общественное мнение. Однако ошибочно думать, что изучением общественного мнения стали заниматься только после принятия вышеупомянутого закона [6]. В 1992 г. Министерством внутренних дел России был принят приказ № 295 «Об организации изучения общественного мнения о деятельности органов внутренних дел». Это был первый нормативный правовой акт, регламентирующий изучение общественного мнения. Следующим документом, рассматривающим общественное мнение как способ оценки правоохранительных органов, является ведомственный приказ «Об утверждении временной инструкции о порядке инспектирования и контрольных проверок и временного руководства по оценке оперативно-розыскной деятельности органов и учреждений внутренних дел» от 9 декабря 1995 г. № 473. В приказе МВД России «О мерах по совершенствованию организации изучения общественного мнения о деятельности органов внутренних дел» от 4 июня 1997 г. № 337 был установлен порядок изучения общественного мнения. Важность этого документа обусловлена тем, что он, во-первых, утверждает регламентирующую порядок фиксации общественного мнения инструкцию, а также рекомендации по обработке и анализу полученных данных, а во-вторых, опреде- 
ляет перечень региональных отделов ВНИИ и вузов МВД России, которые должны проводить социологические исследования в области изучения общественного мнения о деятельности полиции [4].

Далее пришло осознание того, что изучать общественное мнение должны вневедомственные социологические службы. В 2007 г. 30 декабря МВД России был принят приказ № 1246 «О повышении эффективности изучения общественного мнения об уровне безопасности личности и деятельности органов внутренних дел Российской Федерации на основе использования вневедомственных источников социологической информации». Несмотря на то что в соответствии с этим приказом отчеты по результатам социологических исследований готовились вневедомственными организациями, функция компоновки аналитических материалов осталась за ведомствами. Оптимизация и совершенствование органов внутренних дел должны были осуществляться на основе отчетов по изучению общественного мнения. Руководители различного ранга системы МВД обязаны были обеспечить внедрение полученных результатов исследования при подготовке планов работы и управленческих решений [5].

В настоящее время многие специалисты считают, что эффективная оценка правоохранительных органов невозможна без опросов общественного мнения. Оценка эффективности деятельности полиции складывается из целого ряда показателей: стереотипы отношения к правоохранительным институтам, уровень доверия к полиции, ощущение личной безопасности, культура поведения полицейских и т. д. Современные методики, используемые в социологических исследованиях, гарантируют репрезентативность данных. Соответственно данные, полученные в ходе изучения общественного мнения, вполне адекватны и компетентны.

В 2011 г. после принятия Федерального закона «О полиции» был принят приказ МВД РФ «Вопросы оценки деятельности органов внутренних дел РФ» от 29 июня 2011 г. № 735, который определил критерии оценки деятельности ОВД на основе изучения общественного мнения. В Приложении № 1 к данному приказу обозначены следующие критерии: уве- ренность граждан в защищенности своих интересов, личных и имущественных; оценка эффективности деятельности государственного института полиции по защите личных и общественных интересов граждан; готовность граждан оказать поддержку полиции; уровень доверия к полиции. Индикатором оценки деятельности полиции является доля положительных оценок граждан. Таким образом, во всех регионах России с целью определения эффективности деятельности полиции регулярно проводятся мониторинги общественного мнения о деятельности ОВД по вышеупомянутым критериям [3]. Не является исключением и Волгоградская область, где изучением общественного мнения начиная с 1992 г. занимается социологическая группа Волгоградской академии МВД России. Результаты ежегодных социологических исследований доводятся до руководителей ГУ МВД по Волгоградской области с целью принятия решений по оптимизации деятельности полиции ${ }^{2}$.

Дать оценку деятельности органов внутренних дел в Волгограде возможно на основе индикаторов, измерение которых проходило в мае-июне 2016 г. в рамках социологического исследования «Изучение общественного мнения о деятельности полиции». Работа полиции неразрывно связана с вопросами личной безопасности граждан. Оценка личной безопасности граждан складывается под воздействием таких факторов, как психологический дискомфорт, неудовлетворенность различными сторонами жизнедеятельности человека, неуверенность в завтрашнем дне, низкий уровень доверия к государственным институтам. В ходе социологического опроса респондентам был задан вопрос о степени их уверенности в защищенности своих личных и имущественных интересов. Оказалось, что 38,1 \% респондентов стали ощущать себя более защищенными, 27,1 \% - не ощутили изменения по поводу личной безопасности и 25,1 \% ощущают себя менее защищенными. Необходимо отметить, что в 2016 г., по сравнению с 2015 г., не только увеличилась группа респондентов, которые стали ощущать себя менее защищенными (на 12,0 \%), но и повысился уровень тревожности населения Волгограда.

Респонденты, которые выразили полную уверенность в росте защищенности своих лич- 
ных и имущественных интересов, в качестве основных причин этого роста выделили: улучшение работы полиции (39,0\%); усиление бдительности в общественных местах сотрудников охраны $(28,9 \%)$; установка видеокамер в публичных местах (17,4 \%). Ответы на вопpoc, касающийся мер, которые готовы принять для обеспечения собственной безопасности сами респонденты, распределились следующим образом: приобретение средств индивидуальной защиты (30,4 \%); взаимодействие с полицией $(18,9 \%)$; взаимодействие с соседями $(13,1 \%)$; участие в деятельности ДНД (2,0 \%). Самыми опасными общественными местами в городе, по мнению респондентов, остаются дворовые территории и подъезды (32,4 \%); торговые центры, ночные клубы, рестораны (27,6 \%); улицы и парки (22,4\%).

Однако несмотря на проблемы, которые возникают в сфере общественной и личной безопасности, результаты исследования общественного мнения о деятельности полиции во всех субъектах Российской Федерации показали, «что россияне в большинстве своем позитивно оценивают изменения уровня безопасности, произошедшие в их регионе за последние годы. Так, более половины опрошенных (51,0 \%) считают, что в последние годдва стало жить безопаснее» [1]. По сравнению с дореформенным периодом увеличивается количество положительных оценок граждан, выражающих уверенность в защищенности своих личных и имущественных интересов, а также наблюдается позитивная динамика в оценке личной и имущественной безопасности населения. Пусть медленно, но реформа МВД дает свои результаты - граждане наблюдают улучшение работы правоохранительной структуры.

Проблема доверия населения к полиции изучается уже многие годы, но не перестает быть актуальной. Доверие - это наиболее часто используемое понятие в современной России при описании социальных и экономических отношений. Общество не может эффективно функционировать и развиваться, если не заботится об укреплении доверия между различными политическими и социально-экономическими институтами и населением. Благодаря доверию вырабатываются механизмы, которые помогают конструировать современ- ный тип взаимодействия полиции и общества. Высокий уровень доверия населения к полицейским повышает уровень их взаимодействия, способствует стабилизации их отношений, улучшает качество работы сотрудников правоохранительных органов.

Не секрет, что в нашей стране начиная с 90-х гг. наблюдалось снижение уровня доверия населения к правоохранительным органам. Обусловлен данный факт неэффективной борьбой с преступностью, непрофессионализмом, несоответствием морально-этическим требованиям общества, оторванностью правоохранительных структур от интересов населения и т. д. Однако среди экспертов бытует мнение, что за последнее время упавший авторитет сотрудников полиции начинает выправляться и соответственно уровень доверия населения к полиции постепенно растет. Данное мнение подтверждается в ходе проведения социологического исследования в Волгоградском регионе, в ходе которого выяснилось, что в 2016 г. уровень доверия местной полиции составил 62,0 \%. Таким образом, он сохранился на уровне 2014-2015-х гг., что значительно выше, чем в предыдущие годы. Данные результаты характеризуют и общую тенденцию повышения доверия к полиции на территории РФ. Исследование, проведенное ВНИИ МВД России, показало, что «индекс уровня доверия к органам внутренних дел в обеспечении личной и имущественной безопасности в 2014 году составил 66 \%. Самый высокий уровень доверия к полиции продемонстрировало население Крымского федерального округа (83 \%)» [1]. Вместе с тем инициативный всероссийский опрос, проводимый ВЦИОМ в 46 регионах, показывает несколько другие цифры. Согласно данному исследованию только 46,0 \% респондентов доверяют полиции (14,0 \% - определенно доверяют, $32,0 \%$ - скорее доверяют). Тем не менее позитивная динамика все же есть, поскольку, по данным ВЦИОМ, в 2009 г. полиции доверяло $38,0 \%$ опрошенных, а в 2012 г. - $35 \%$ [2].

Немаловажным показателем доверия граждан к правоохранительным органам является их обращение в ОВД за помощью. В ходе опроса выяснилось, что среди граждан, которые подвергались преступным посягательствам, только 62,0 \% обратились в 
ОВД. Остальные респонденты, подвергшиеся преступным посягательствам, в ОВД не обратились, поскольку 17,6 \% опрошенных считают, что им был нанесен незначительный ущерб, 42,0 \% боялись потерять время, 13,3\% не верили, что им помогут. К сожалению, среди тех, кто все-таки обратился за помощью к полиции, только 68,8 \% «удовлетворены» мерами, принятыми ОВД по поводу их обращения, остальные соответственно «не удовлетворены».

Одним из показателей доверия граждан к правоохранительным органам является оказание ими помощи сотрудникам полиции. В ходе изучения общественного мнения о деятельности полиции выяснилось, что не все граждане готовы оказывать помощь органам внутренних дел. Уровень содействия полиции, судя по ответам респондентов, остается таким же, как и в прошлом году. Так, в 2013 г. $13,7 \%$, в 2014 г. $-14,6 \%$, в 2015 г. $-16,0 \%$, в 2016 г. - 19,9\% опрошенных оказывали помощь сотрудникам полиции.

На вопрос «Готовы ли вы в дальнейшем оказывать помощь полиции?» количество респондентов, ответивших «безусловно, да», осталось на уровне 2014 г. (41,4\%). Вместе с тем на $5 \%$ уменьшилось количество респондентов, готовых оказывать помощь при определенных условиях, и увеличилось количество неготовых оказывать содействие полиции.

В социологическом исследовании была поставлена задача - определить, какую конкретно помощь респонденты готовы оказывать полиции. Оказалось, что сообщить информацию о готовящемся или совершенном преступлении готовы $68,6 \%$; принять участие в охране общественного порядка - $14 \%$; выполнять отдельные поручения - 7,7\%; сотрудничать негласно - 9,4 \%. В анкете также был поставлен вопрос о готовности респондентов негласно сотрудничать с полицией. Оказалось, что $19 \%$ опрошенных согласились бы сотрудничать, не раздумывая, и еще 32,6 \% - при определенных условиях. Отказались бы сотрудничать негласно 43,1 \% респондентов. Среди причин неготовности негласно сотрудничать с полицией основными являются: личные убеждения $-52 \%$, недоверие полиции - $17,9 \%$, негативная оценка данного поступка окружающими $-13,3 \%$, нормы морали - 13,3\%.
Отношение к полиции со стороны населения во многом зависит от поведения сотрудников ОВД. Вызывает тревогу тот факт, что $20 \%$ респондентов отметили, что им приходилось наблюдать действия сотрудников ОВД, при которых допускались нарушения прав граждан. Среди них опрошенные выделили: проявление жестокости - $24 \%$; грубость, бестактность - 26,6 \%; вымогательство, поборы - $20 \%$; использование служебного положения в личных целях - 30 \%; искажение фактов $-15,5 \%$.

Таким образом, исходя из социологических данных, полученных в ходе изучения общественного мнения о деятельности полиции, мы можем констатировать, что, несмотря на наметившуюся позитивную динамику, касающуюся оценки гражданами деятельности полиции, еще имеется достаточный резерв для конструктивного сотрудничества населения и сотрудников ОВД. Неоценимым резервом в повышении эффективности деятельности полиции является постоянный мониторинг общественного мнения. Именно качественная оценка деятельности органов внутренних дел позволяет выявить наиболее проблемные участки в их деятельности, требующие экстренного воздействия. Полагаясь на общественное мнение, мы получим мощный объективный инструмент оценки деятельности полиции. Только открытый диалог с гражданским обществом способен привести к тому, что полиция будет способна воспринимать от населения конструктивные предложения по оптимизации своей деятельности. Соответственно изучение общественного мнения на сегодняшний момент является мощным инструментом, позволяющим улучшить деятельность полиции.

\section{ПРИМЕЧАНИЯ}

1 Исследование выполнено при финансовой поддержке РФФИ и Администрации Волгоградской области, проект «Разработка модели общественного контроля за деятельностью органов внутренних дел: региональный аспект» № 17-13-34023.

${ }^{2}$ Ежегодный мониторинг общественного мнения о деятельности полиции проводится по заказу ГУВД Волгоградской области с 1998 по 2016 год. Выборочная совокупность - 500 человек, тип выборки - серийно-стратифицированная. 


\section{СПИСОК ЛИТЕРАТУРЫ}

1. Аналитический отчет по теме: «Исследование общественного мнения о деятельности органов внутренних дел (полиции) в 85 субъектах Российской Федерации». - Электрон. текстовые дан. Режим доступа: https://27.мвд.рф/ upload/site30/ document_file/kSdTvGiAdy.doc (дата обращения: 12.01.2017). - Загл. с экрана.

2. Полиция: вчера и сегодня // Пресс-выпуск № 2969. - Электрон. текстовые дан. - Режим доступа: https://wciom.ru/index.php?id=236\&uid=115453 (дата обращения: 12.01.2017). - Загл. с экрана.

3. Приказ МВД РФ «Вопросы оценки деятельности органов внугренних дел РФ» от 29 июня 2011 г. № 735. - Электрон. текстовые дан. - Режим доступа: http://docs.cntd.ru/document/902294114 (дата обращения: 10.02.2017). - Загл. с экрана.

4. Приказ МВД РФ «О мерах по совершенствованию организации изучения общественного мнения о деятельности органов внугренних дел» от 4 июня 1997 г. № 337. - Электрон. текстовые дан. Режим доступа: http://base.garant.ru/1350162/\#text (дата обращения: 10.02.2017). - Загл. с экрана.

5. Приказ МВД РФ «О повышении эффективности изучения общественного мнения об уровне безопасности личности и деятельности органов внутренних дел Российской Федерации на основе использования вневедомственных источников социологической информации» от 30 дек. 2007 г. № 1246. - Электрон. текстовые дан. - Режим доступа: https://71.мвд.рф/upload/site72/document_file/ 1246_ot_30.12.2007.doc (дата обращения: 10.02.2017). Загл. с экрана.

6. Федеральный закон «О полиции» от 7 февр. 2011 г. № 3-Ф3 : (в послед. ред.). - Электрон. текстовые дан. - Режим доступа: http://www.consultant.ru/ document/cons_doc_LAW_110165/ (дата обращения: 10.01.2017). - Загл. с экрана.

\section{REFERENCES}

1. Analiticheskiy otchet po teme: «Issledovanie obshchestvennogo mneniya o deyatelnosti organov vnutrennikh del (politsii) v 85 subyektakh Rossiyskoy Federatsii» [The Analytical Report on the Subject:
"Research of Public Opinion on the Activities of Law Enforcement Bodies (Police) in 85 Subjects of the Russian Federation"]. URL: https://27.md.rf/upload/ site30/document_file/ kSdTvGiAdy.doc. (accessed January 12, 2017).

2. Politsiya: vchera i segodnya [The Police: Yesterday and Today]. Press-vypusk № 2969 [Press Release no. 2969]. URL: https://wciom.ru/index. php?id=236\&uid=115453. (accessed January 12, 2017).

3. Prikaz MVD RF «Voprosy otsenki deyatelnosti organov vnutrennikh del RF》 ot 29 iyunya 2011 g. № 735 [The Decree of the Ministry of Internal Affairs of the Russian Federation "Issues of Assessing the Activity of Law-Enforcement Bodies of the Russian Federation" of June 29, 2011 no. 735]. URL: http:// docs.cntd.ru/document/902294114. (accessed February 10, 2017).

4. Prikaz MVD RF $« O$ merakh po sovershenstvovaniyu organizatsii izucheniya obshchestvennogo mneniya o deyatelnosti organov vnutrennikh del» ot 4 iyunya 1997 g. № 337 [The Decree of the Ministry of Internal Affairs of the Russian Federation "On Measures to Improve the Organization of Studying Public Opinion on the Activity of Law Enforcement Bodies" of June 4, 1997 no. 337]. URL: http://base.garant.ru/1350162/\#text. (accessed February 10, 2017).

5. Prikaz MVD RF «O povyshenii effektivnosti izucheniya obshchestvennogo mneniya ob urovne bezopasnosti lichnosti $i$ deyatelnosti organov vnutrennikh del Rossiyskoy Federatsii na osnove ispolzovaniya vnevedomstvennykh istochnikov sotsiologicheskoy informatsii» ot 30 dek. $2007 \mathrm{~g}$. № 1246 [The Decree of the Ministry of Internal Affairs of the Russian Federation "On Increasing the Effectiveness of Studying Public Opinion on the Level of Personal Security and the Activities of Law Enforcement Bodies of the Russian Federation on the Basis of Non-Departmental Sources of Sociological Information" of December 30, 2007 no. 1246]. URL: https://71.мвд.pф/upload/site72/document_file/ 1246_ot_30.12.2007.doc. (accessed February 10, 2017).

6. Federalnyy zakon «O politsii» ot 7 fevr. 2011 g. № 3-FZ: (v posled. red.) [The Federal Law "On the Police" of February 7, 2011 no. 3-FL (last version)]. URL: http://www.consultant.ru/document/cons_doc_ LAW_110165/. (accessed January 10, 2017). 


\section{СОЦИОЛОГИЯ И СОЦИАЛЬНЫЕ ТЕХНОЛОГИИ}

\section{Information About the Author}

Olga V. Zueva, Candidate of Sociological Sciences, Associate Professor, Department of Philosophy, Volgograd Academy of the Russian Internal Affairs Ministry, Istoricheskaya St., 130, 400089 Volgograd, Russian Federation, olgazueva-1@rambler.ru.

\section{Информация об авторе}

Ольга Владимировна Зуева, кандидат социологических наук, доцент кафедры философии, Волгоградская академия МВД России, ул. Историческая, 130, 400089 г. Волгоград, Российская Федерация, olgazueva-1@rambler.ru. 